\title{
Factors Driving Learner Success in Online Professional Development
}
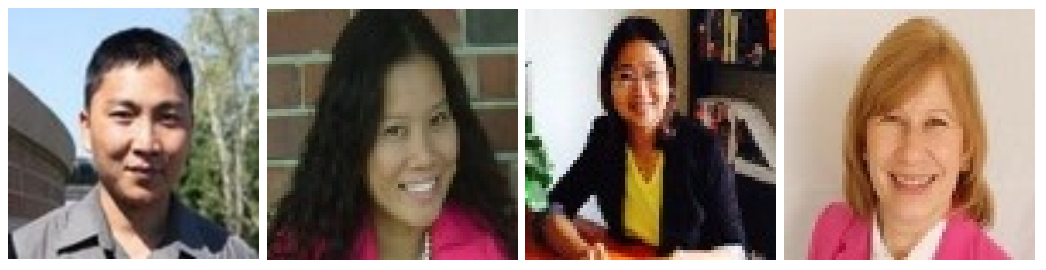

$\mathrm{Phu} \mathrm{Vu}^{1}$, Vien $\mathrm{CaO}^{2}$, Lan $\mathrm{Vu}^{2}$, and Jude Cepero ${ }^{1}$

${ }^{1}$ University of Nebraska Kearney, USA, ${ }^{2}$ Southern Illinois University, USA

\section{Abstract}

This study examined factors that contributed to the success of online learners in an online professional development course. Research instruments included an online survey and learners' activity logs in an online professional development course for 512 in-service teachers. The findings showed that there were several factors affecting online learners' success in online professional development. In addition, there were also significant differences between successful and unsuccessful online learners in terms of course login frequency and learning activities viewed.

Keywords: Online learners; in-service teachers; online professional development; learners' success; online training; OPD 


\section{Introduction}

Professional development refers to the process of learning and keeping up-to-date in one's area of expertise both for personal development and for career advancement. Those who engage in professional development are interested in increasing their own skills/knowledge, enhancing their ability to do their work, and lifelong learning. Professional development includes

all the natural learning experiences and those conscious and planned activities which are intended to be of direct or indirect benefit to the individual, group or school and which contribute through these to the quality of education in the classroom. (Day, 1999, p. 4)

In teacher education, professional development generally refers to ongoing learning opportunities available to teachers and other education personnel. In the United States, the need for professional development of school staff came to the forefront in the 1960's (Murphy-Latta, 2008). With schools today facing numerous complex challenges - from working with an increasingly diverse population of students, to meeting rigorous academic standards and goals, to integrating new technology in the classroom authorities continue to stress the need for teachers to be able to enhance and build on their instructional knowledge. Under these challenges, the education and professional development of teachers is considered as the central component of educational improvement (Hawley \&Valli, 1999).

It is reported that the ongoing, job-embedded, professional growth of teachers will lead to high achieving schools (Kelleher, 2003). Essentially, professional development has been adopted as a policy solution to improving the number of highly qualified teachers as well as helping all students to achieve high academic standards (Colbert, Brown, Choi, \& Thomas, 2008).

\section{Online Professional Development (OPD)}

Online teacher professional development (OPD) is popular due to the need for professional development that can fit teachers' busy schedules and that provides access, as well as ongoing support, to important resources not otherwise affordable or even available locally (Dede et. al, 2009). OPD provides flexibility by allowing participants, irrespective of location, to manage educational pursuits with work and personal responsibilities (Stanford-Bowers, 2008). In addition, OPD can be offered in various forms: distance learning classrooms enabling individuals to participate in a class via video conferencing with the goal of making the online experience as close as possible to an in-class experience; an online asynchronous course negating the need for all the participants of a course to be available at the same time and allowing participants to complete course requirements according to their individual schedule; and self-paced 
online courses allowing each participant to work through a series of resources and activities at his or her own pace (Russell, Carey, Kleiman, \& Venale, 2009).

Because of its advantages, OPD has received rapid attention recently. Indeed, according to the findings of the Speak Up 2012 survey, "From Chalkboards to Tablets: The Digital Conversion of the K-12 Classroom" as reported in Cavanagh (2013), the percentages of teachers and principals participating in online classes, webinars, and virtual professional learning communities rose significantly during the time period of 20082013. In addition, the number of principals who reported they support professional growth through some form of social networking more than tripled, from $8 \%$ in 2008 to $25 \%$ today.

Given the importance of professional development for teachers and the increasingly popular trend of online professional development for teachers, this study seeks to examine what factors drive learners' success in that online training environment.

\section{Literature Review}

Online education literature is often characterized by its focus on "how to" teach online and how to optimally utilize the various features available in most instructional platforms, generally based on authors' experiences teaching in this setting or on instructors' feedback. There is less evidence of student-oriented analysis such as online student behaviors, performances, attitudes, or preferences (Beaudoin, Kutz, \& Eden, 2009). Sharing similar viewpoints, Coates (2006) maintains that, despite the proliferation of studies into online education in the past decade and widespread levels of adoption, most research has focused on financial, technical, and administrative aspects of these learning systems. In particular, Coates notes, there are very few published works on online student engagement.

\section{The Characteristics of Successful Online Learners}

Palloff and Pratt (2001) listed the characteristics of successful online learners. According to the researchers, successful learners are seen as volunteers seeking further education, having higher expectations, being more self-disciplined, older, enjoying learning for its own sake, demonstrating good thinking skills, able to work independently with limited structure, and recognizing the value of interacting with other online peers.

Boyd (2004) reviewed current literature and research in online learners and described characteristics of successful online students. The researcher considered four sets of factors: 1) the technical factors, which pertain to the student's access to the technology through which an online course is delivered; 2) the environmental factors, which have to do with the student's personal learning environment; 3) the personal factors, which have to do with the character traits of the students themselves; and 4) various learning 
characteristics, which successful online students tend to exhibit and possess. In terms of technical issues, a successful online student must possess appropriate technology and the skills to use that technology effectively. Regarding environmental factors, students must have an appropriate management of time and space, as well as support from significant others. As far as personal factors are concerned, the students must possess a healthy balance between autonomy and interactivity, self-motivation and self-discipline, and a high level of integrity. Finally, the students must possess various learning characteristics such as a more independent learning style that tends toward a more selfdirected learning orientation, as well as better-than-average reading and writing skills.

Recently, Beaudoin, Kutz, and Eden (2009) administered a 58-item survey to 318 respondents in four cohorts: Western (mostly the U.S.), J apan, Mexico, and Israel. One of the research problems of the study was to find out the items critical to learner success in e-learning. The questionnaire listed 10 items generally considered to be critical elements for successful online learning and then asked respondents to add two additional ones of their own. It should be noted that as participants were from different countries, it is possible that they had different responses because of their respective cultures. As a result, the researchers reported their findings according to cohorts.

The majority of the participants indicated that success of online learners ultimately depended more on self-determination than on institutional support. Except for the Mexican respondents, the strongest determinants for success among these online learners were related to learner attributes such as self-motivation, followed by time management, then capacity to learn with limited support. This result would indicate that, for most of these students, online learning success emanates from the learner, rather than from characteristics related to the learning environment such as courses. The least critical items to the respondents were: ability to cope with unstructured settings, familiarity with technology, and relationships with other online learners.

In agreement with findings by Beaudoin et. al (2009), Sun (2014) reported results obtained from qualitative and quantitative data that online learning success came from learners. The participants in Sun commented that self-motivation, self-directed learning, and self-regulation of learning were the key factors in online learning success. The factor of self-regulation of learning includes skills such as setting goals, orienting action accordingly, planning, monitoring, asking for help when needed, trying out different strategies, and reflecting (Guichon, 2009; Hurd, 2006; Wang, 2010).

Learner self-efficacy is critical in online learning (Cho \&J onassen, 2009; Cho, Shen, \& Laffey, 2010) and can be a key factor in this challenging learning environment (Hodges, 2008). A significant, moderate, and positive relationship between online technological self-efficacy and online academic achievement was found in McGhee (2010). Womble (2008) found a significant and positive correlation between e-learning self-efficacy and e-learner satisfaction. In addition, computer self-efficacy was a significant predictor of online learners' satisfaction and their intention to take future online courses (Lim, 2001). 


\section{Successful Learners in OPD}

Specifically, in the case of professional development and OPD, the vast majority of research has focused on design features that increase engagement and course quality, and on the subsequent effect that professional development and OPD have on teacher knowledge and practice (O’Dwyer et. al, 2010; Treacy, Kleiman, \&Peterson, 2002; Yang $\& \mathrm{Liu}, 2004)$. As mentioned above, in an effort to increase access and convenience and to improve cost efficiency, there has been growing interest in OPD (Dede, 2006; Ginsburg, Gray, \& Levin, 2004). In recent years, there have been urges to rigorously examine the impacts of OPD (Dede, Ketelhut, Whitehouse, Breit, \&McCloskey, 2009). A main concern raised by Stes, De Maeyer, Gijbels, and Van Petegem (2012) was that most research in professional development lacks robust analyses of the characteristics of participants who complete such professional development programs successfully.

A search of the literature related to factors driving learner success in OPD is limited by the scarcity of scholarship on the topic. The study by Rienties, Brouwer, and Lygo-Baker (2013) examined how successful participants differed from unsuccessful participants. The study involved 73 participants. The researchers explored whether the 40 participants who successfully completed the OPD module had different teacher beliefs, intentions, and Technological Pedagogical Content Knowledge scores at the start of the course than the 33 participants who dropped out. Findings showed that participants who failed the training program had significantly higher scores on teacher beliefs towards training students for jobs in comparison with academics who completed the OPD program successfully. Additionally, the amount of time spent in the webvideoconference system during the training program was a noticeable difference. Successful participants on average spent 4 hours and 59 minutes attending and/or watching the web-videoconferencing sessions in Adobe Connect while unsuccessful counterparts only spent 2 hours and 18 minutes.

Significant differences were also found in passing rates across institutions and disciplines. The number of successful participants was significantly higher in particular institutions. Academics from particular specialty areas were more likely to drop out. However as not all institutions and disciplines had a sufficiently large sample size, more research is needed to generalize the conclusion that institutional and disciplinary differences influence learner success. In terms of technological competencies, the researchers did not find any indication that the technological pedagogical content knowledge appeared to affect the retention of participants on the OPD program. Indeed, previous experience with technology did not seem to impact upon engagement and retention. 


\section{Methodology}

Data for this study were collected from two different sources for the triangulation purpose to increase the reliability and validity of the findings. Those sources included an online survey and learners' activity logs in an online professional development course for 512 in-service teachers. Heiervang and Goodman (2011) held that online surveys may have advantages in terms of the speed and cost of data collection as well as data quality. However, they may be biased by low and selective participation. To minimize the disadvantages of the online survey, we used learners' activity logs as an existing data source. According to Shultz, Hoffman, and Reiter-Palmon (2005), existing data are objective and relatively easy to transfer and store, but they are also not always a perfect fit between what the researchers are trying to measure and the purposes for which the data were collected. To reduce the drawbacks of those sources of data, the triangulation process was used. According to Maxwell (2005), the triangulation process of collecting information from different sources using a variety of methods reduced the risk that conclusions would reflect systematic biases and allowed a broader understanding of the study's issues. The comparison of data gathered supported the triangulation process and therefore enhanced internal validity. Efforts to control any threats to theoretical validity were also conducted by collecting and drawing attention to any discrepant data or alternative explanations.

\section{Data Collection Procedures}

In 2013, we hosted an open online professional training course in computer-assisted language learning (CALL) for 512 in-service language teachers from 23 countries. This six week long course was the first course of our professional development course series whose goal was to improve language teachers' technology competences. At the end of the training course, 153 learners who completed the course with the total grade of at least 80 out of 100 were granted a certificate of successful completion in our CALL course. We had access to these 153 learners' email addresses to contact them and invite them to participate in this study. Within a month of three times of sending emails asking for their participation, 142 (93\%) responded to our online survey.

The online survey had three questions. The first question asked about participants' age range. We took the age ranges popularly used by the Gallop Poll as follows for our study. 
Table 1

Age Range

\begin{tabular}{|l|l|}
\hline 1 & Under 12 years old \\
\hline 2 & $12-17$ years old \\
\hline 3 & $18-24$ years old \\
\hline 4 & $25-34$ years old \\
\hline 5 & $35-44$ years old \\
\hline 6 & $45-54$ years old \\
\hline 7 & $55-64$ years old \\
\hline 8 & $65-74$ years old \\
\hline 9 & 75 years or older \\
\hline
\end{tabular}

The second question asked the participants to select factors that they thought were the most important factors to drive their successful completion of the course. Based on studies conducted by Boyd (2004) and Beaudoin, Kurtz, and Eden (2009), we created a list of factors considered critical to being successful online learners as shown below.

- Ability to self-manage my time

- Often checking email

- Ability to learn with limited support

- Relationships with online instructors

- Reliable internet connection

- Course login frequency

- Confidence to be able to achieve the learning goals

- Good hardware especially computers

- Ability to express my ideas

- Ability to cope with non-structured settings

- Relationships with other online learners

- Familiarity with technology

- $\quad$ Self- discipline

These factors were presented as a list which research participants simply ticked.

The last question was an open-ended question asking the participants to provide any other important factors that were not available in the list. They could also make comments on those factors.

The second data source was learners' activity logs in the CALL course. The lead researcher was granted an access permit to get access to the online learning management system as an administrator to download the activity logs of all 525 learners in the CALL course. These logs kept a record of all the activities each learner performed 
during the course. We sorted them into two lists of activity logs. One list had 153 activity logs of 153 learners who completed the course with the total grade of at least 80 out of 100. The other list had 153 activity logs of 153 learners who had the lowest grades. Those learners who dropped out were not included in this study.

A reliability test was conducted for the total data to identify whether the grades on the lists had acceptable internal consistency. The grade list was tested using Cronbach's alpha. The resulting alpha value was .88 which according to George and Mallery (2009) indicates good internal consistency reliability. One independent-samples t-test was run to identify whether there were any significant differences in terms of course login frequency between the two groups of participants with highest grades and lowest grades. An Excel-based calculation was used to identify what learning activities learners in each group viewed the most. Below is a sample of one learner's activity log in the online course. 


\begin{tabular}{|c|c|c|c|c|}
\hline Time & IP address & User full name & Action & Information \\
\hline Mon 15 July 2013, 04:54 AM & 123.19.37.91 & Lan Le & forum view forum & General Discussion Forum \\
\hline Mon 15 July 2013, 04:54 AM & 123.19.37.91 & Lan Le & course view & Introduction to Computer-Assisted Language Learning \\
\hline Mon 15 July 2013, 04:54 AM & 123.19.37.91 & Lan Le & forum view forum & Bulletin Board \\
\hline Mon 15 July $2013,04: 54$ AM & 123.19.37.91 & Lan Le & course view & Introduction to Computer-Assisted Language Learning \\
\hline Mon 8 July 2013, 02:50 PM & 123.19.43.32 & Lan Le & forum view forum & General Discussion Forum \\
\hline Mon 8 July 2013, 02:50 PM & 123.19 .43 .32 & Lan Le & course view & Introduction to Computer-Assisted Language Learning \\
\hline Mon 8 July $2013,02: 50$ PM & 123.19 .43 .32 & Lan Le & forum view forum & Bulletin Board \\
\hline Mon 8 July $2013,02: 50$ PM & 123.19 .43 .32 & Lan Le & forum view discussion & Validating your final grade \\
\hline Mon 8 July $2013,02: 49$ PM & 123.19 .43 .32 & Lan Le & course view & Introduction to Computer-Assisted Language Learning \\
\hline Tue 2 July $2013,05: 25$ AM & 123.19 .40 .126 & Lan Le & course view & Introduction to Computer-Assisted Language Learning \\
\hline Tue 2 July $2013,05: 25$ AM & 123.19 .40 .126 & Lan Le & course view & Introduction to Computer-Assisted Language Learning \\
\hline Tue 2 July 2013, 05:24 AM & 123.19.40.126 & Lan Le & forum view forum & General Discussion Forum \\
\hline Tue 2 July 2013, 05:24 AM & 123.19.40.126 & Lan Le & course view & Introduction to Computer-Assisted Language Learning \\
\hline Tue 2 July $2013,05: 23$ AM & 123.19 .40 .126 & Lan Le & forum view discussion & Validating your final grade \\
\hline Tue 2 July 2013, 05:22 AM & 123.19 .40 .126 & Lan Le & course view & Introduction to Computer-Assisted Language Learning \\
\hline Mon 1 July $2013,02: 58$ PM & 123.19.44.149 & Lan Le & page view & Resources \\
\hline Mon 1 July 2013, 02:57 PM & 123.19.44.149 & Lan Le & course view & Introduction to Computer-Assisted Language Learning \\
\hline Mon 1 July 2013, 02:11 PM & 123.19 .34 .3 & Lan Le & page view & Articles \\
\hline Mon 1 July 2013, 02:11 PM & 123.19 .34 .3 & Lan Le & course view & Introduction to Computer-Assisted Language Learning \\
\hline Mon 1 July 2013, 02:11 PM & 123.19 .34 .3 & Lan Le & forum view forum & General Discussion Forum \\
\hline Mon 1 July 2013, 02:11 PM & 123.19 .34 .3 & Lan Le & course view & Introduction to Computer-Assisted Language Learning \\
\hline Mon 1 July 2013, 08:21 AM & 123.19.44.235 & Lan Le & forum view discussion & Message from Dr. T \\
\hline Mon 1 July 2013, 08:20 AM & 123.19.44.235 & Lan Le & forum view forum & General Discussion Forum \\
\hline Mon 1 July 2013, 08:20 AM & 123.19.44.235 & Lan Le & course view & Introduction to Computer-Assisted Language Learning \\
\hline Mon 1 July 2013, 04:32 AM & 123.19.34.85 & Lan Le & forum view discussion & Farewell and Thank you! \\
\hline Mon 1 July 2013, 04:31 AM & 123.19 .34 .85 & Lan Le & forum view forum & General Discussion Forum \\
\hline Mon 1 July 2013, 04:31 AM & 123.19.34.85 & Lan Le & course view & Introduction to Computer-Assisted Language Learning \\
\hline
\end{tabular}

\section{Figure 1. Screenshot of a learner's login activity.}




\section{Findings}

\section{Online Survey Results}

The first question in the online survey asked about the age range of online learners who completed the online professional training course with the total grade of at least 80 out of 100. The most common age range reported in this online survey was 25-34 as shown in Figure 2. Seventy-six out of 93 online learners, accounting for 70.7\%, who finished the online professional training course with the total grade of at least 80 out of 100 identified themselves in the 25-34 age range. The 35-44 age range was the second most common $(n=12)$. The third most common age range was 18-24 $(n=5)$.

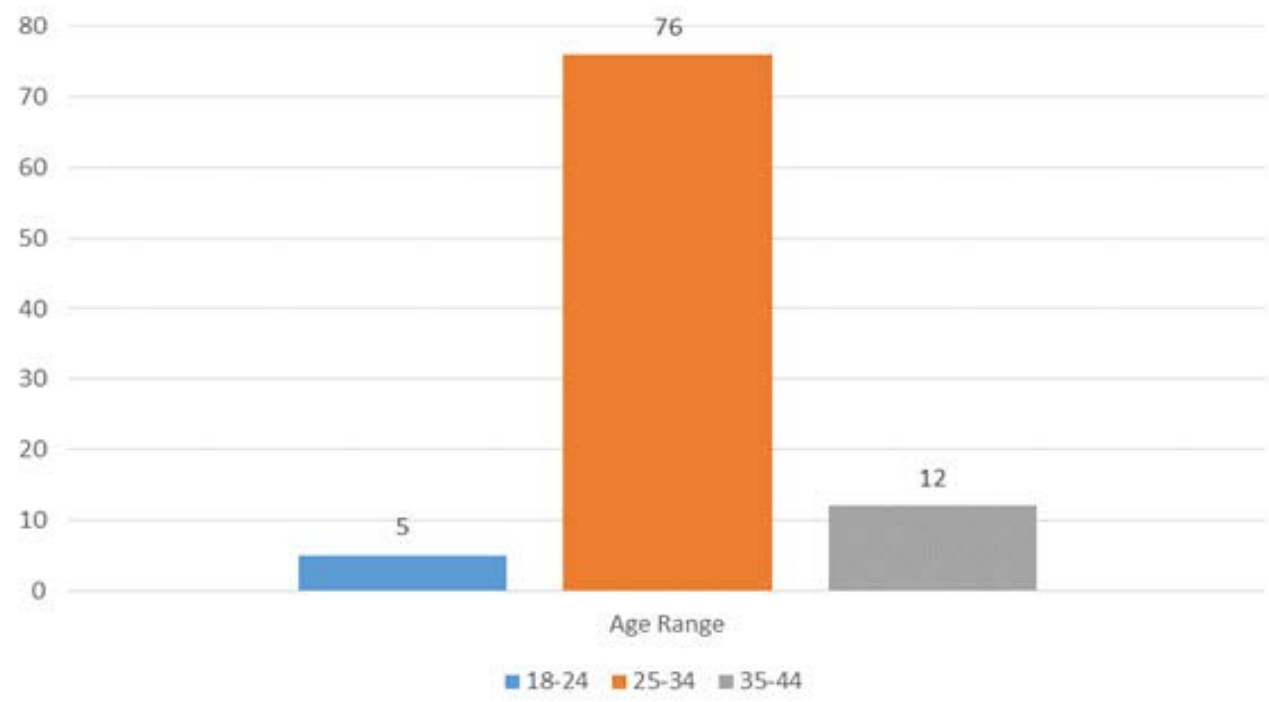

Figure 2. Online learners' age ranges.

The second and third questions asked the participants to select factors they considered the most important leading to their successful completion of the online professional training course. In the second question, participants were provided with a list of 13 factors for them to select. In the third question, participants were given an option to provide factors they thought important to their success in the online professional training that were not mentioned in the second question. We used two common techniques in qualitative research to identify themes emerging from participants' responses to the open-ended question. The first technique is "word repetition". Words that are frequently repeated are often considered as being salient in the minds of respondents. D'Andrade (1995) observed that the simplest and most direct indication of schematic organization in naturalistic discourse is the repetition of associative linkages. 
The second technique is "Key-Word-In-Context" (KWIC). KWIC is based on a simple rule: If you want to understand a certain concept, look at how it is used in the context. Simply put, in this technique, researchers identify key words and then systematically find the corpus of text to look for all the connections and relationships of the words or phrases in the context.

As shown in Figure 3, "Self-discipline" was considered the most decisive factor leading to success in online professional training (90/93 respondents). The second factor was "School administrators' expectation" (89/93 respondents). This factor was not included in our list of important factors leading to successful online learners found in studies by Boyd (2004) and Beaudoin, Kurtz, and Eden (2009), but emerged from our open-ended question. The third critical factor was the "Ability to learn with limited support" (87/93 respondents). On the other pole of decisive factors, "Relationship with online instructors" was the least important factor leading to success in online professional training (30/93 respondents). 


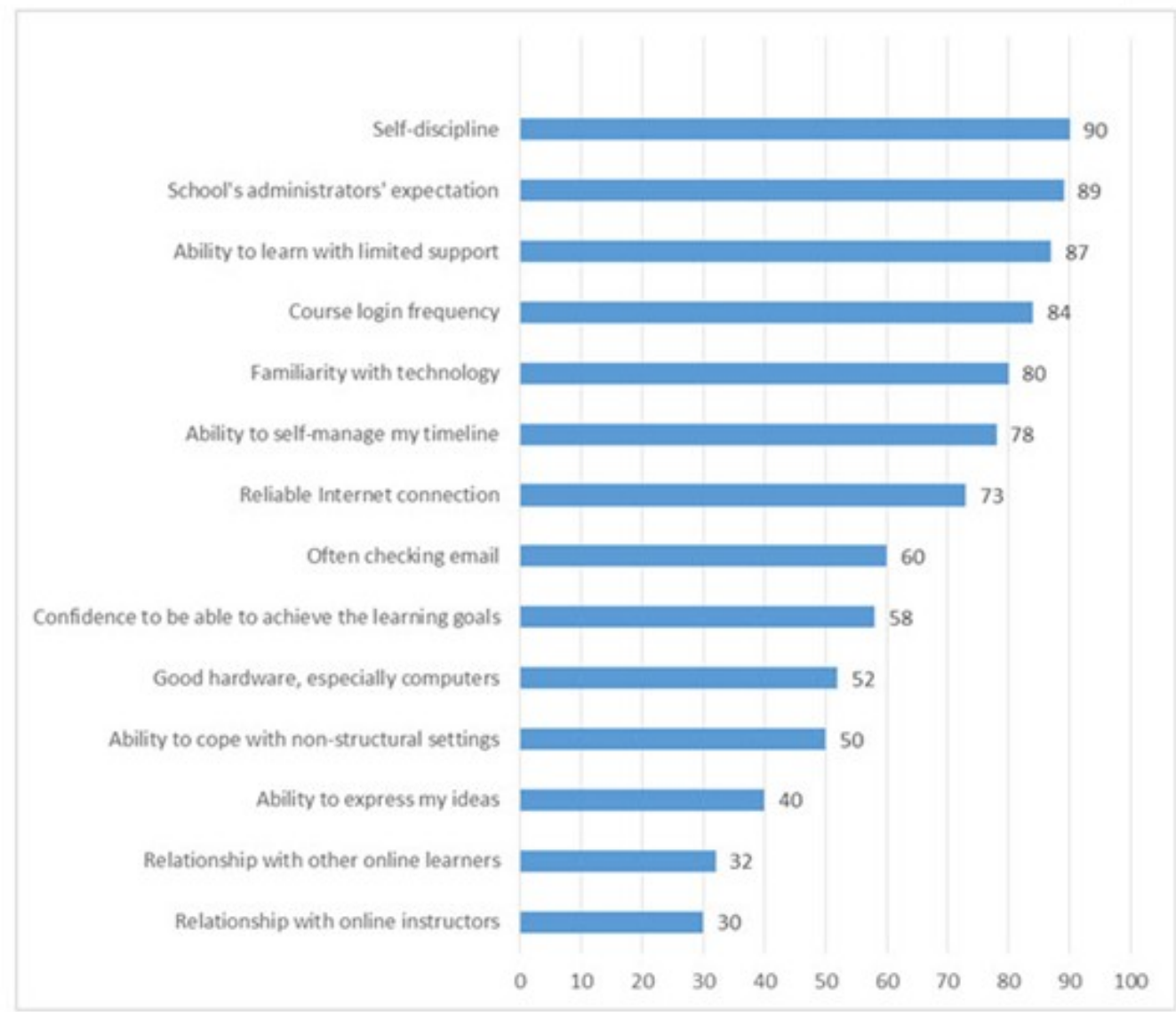

Figure 3. Factors leading to successful completion of the online professional training course.

\section{Learners' Login Analysis}

\section{Learners' login frequency.}

The online professional training course lasted over 42 days (six weeks). In many cases, based on the interludes within a day, we could assume that learners logged into the course several times per day. However, this counting method may not be completely accurate because many interludes were not obvious. Therefore, we decided to count all of the login attempts in one day as one login attempt/ unit. For example as shown in the login log below, one learner may have logged into the online course three times or four times on Monday, J uly 01, 2013, but we counted it as only one login attempt/ unit. 


\begin{tabular}{|c|c|c|c|c|}
\hline Mon 1 July 2013, 02:57 PM & 123.19.44.149 & Lan Le & course view & Introduction to Computer-Assisted Language Learning \\
\hline Mon 1 July 2013, 02:11 PM & 123.19 .34 .3 & Lan Le & page view & Articles \\
\hline Mon 1 July 2013, 02:11 PM & 123.19 .34 .3 & Lan Le & course view & Introduction to Computer-Assisted Language Learning \\
\hline Mon 1 July 2013, 02:11 PM & 123.19 .34 .3 & Lan Le & forum view forum & General Discussion Forum \\
\hline Mon 1 July 2013, 02:11 PM & 123.19 .34 .3 & Lan Le & course view & Introduction to Computer-Assisted Language Learning \\
\hline Mon 1 July 2013, 08:21 AM & 123.19.44.235 & Lan Le & forum view discussion & Message from Dr. T \\
\hline Mon 1 July 2013, 08:20 AM & 123.19.44.235 & Lan Le & forum view forum & General Discussion Forum \\
\hline Mon 1 July 2013, 08:20 AM & 123.19.44.235 & Lan Le & course view & Introduction to Computer-Assisted Language Learning \\
\hline Mon 1 July 2013, 04:32 AM & 123.19 .34 .85 & Lan Le & forum view discussion & Farewell and Thank you! \\
\hline Mon 1 July 2013, 04:31 AM & 123.19 .34 .85 & Lan Le & forum view forum & General Discussion Forum \\
\hline Mon 1 July 2013, 04:31 AM & 123.19 .34 .85 & Lan Le & course view & Introduction to Computer-Assisted Language Learning \\
\hline
\end{tabular}

Figure 4. Screenshot of a learner's login activity.

An independent-samples t-test was conducted to compare 153 learners with 80 and above grades (Group A) and 153 learners with the lowest grades (Group B) in terms of how often they logged into their online professional training course. The result from the t-test showed that there was a significant difference in the login frequency for Group A ( $\mathrm{n}=153, \mathrm{M}=38.76, \mathrm{SD}=5.13$ ) and Group $\mathrm{B}(\mathrm{n}=153, \mathrm{M}=15.21, \mathrm{SD}=5.13)$; $\mathrm{t}$ (1) $=25.60, \mathrm{p}=0.001$. These results suggested that learners in Group A logged into the course far more often than their peers in Group B. On average, during a 42 day (six week) period of the course, a learner in group A made 39 login attempts while a learner in Group B made 15 login attempts.

\section{Learning activities viewed by learners.}

The format of the online training course in this study had seven sections, among which were one general section and six module sections for six weeks. In the general section, there was a bulletin board where the instructor and/or course coordinators posted course announcements and/or course updates. Learners could view the bulletin board but could not post there. The second component in the general section was a discussion forum that had several sub-forums such as "General Discussion Forum", "Questions for Weekly Lectures", "Technical Problems". The third component was "Virtual Office Hours" where online learners could enter to have live online interactions with the instructor and/or course coordinators, similar to traditional office hours. The fourth component was an artificial intelligence online chat forum where online learners could chat 24/ 7 with a robot about any topic they were interested in. The fifth component in this section was a "Course Orientation Video Clip" where the instructor provided basic 
instructions about how to navigate and complete the course successfully. The last component was learners' gradebook where they could check their weekly grades. Following the general section were six sections or weekly modules for six weeks. Each weekly module had an approximately 20-minute video-based lecture. The second learning activity in each weekly module was "Learning Resources" where learners found reading articles and web-based tools related to the topic of the week. The third learning activity was "Weekly Assignment" where learners did and submitted their assignments.

To identify learning activities viewed by learners in the two groups, the researchers gave each learning activity a specific code. For example, the learning activity "Bulletin Board" was coded as A while "General Discussion Forum" was coded as B. All those learning activities were input into a Microsoft Excel sheet to calculate the total number for each learning activity. As shown in Figure 5, except the three learning activities "Questions for Weekly Lectures, Technical Problems, and Virtual Office Hours", learners in Group A participated in learning activities quite equally. The most-viewed activity was "Learning Resources". The least frequently viewed activity was "Technical Problems". Differently, for learners in Group B, "Technical Problems" and "Questions for Weekly Lectures" were only two learning activities learners in this group most frequently viewed. The viewing rates of other activities were very low compared with the viewing rates by learners in Group A. Statistically, there was a significant difference between learners in Group A and learners in Group B in terms of learning activity viewed by Group A ( $\mathrm{M}=4938.64, \mathrm{SD}=1969.91)$ and Group B $(\mathrm{M}=1571.72 .30, \mathrm{SD}=1977.13)$; $\mathrm{t}(1)$ $=3.76, p=0.0013$. 


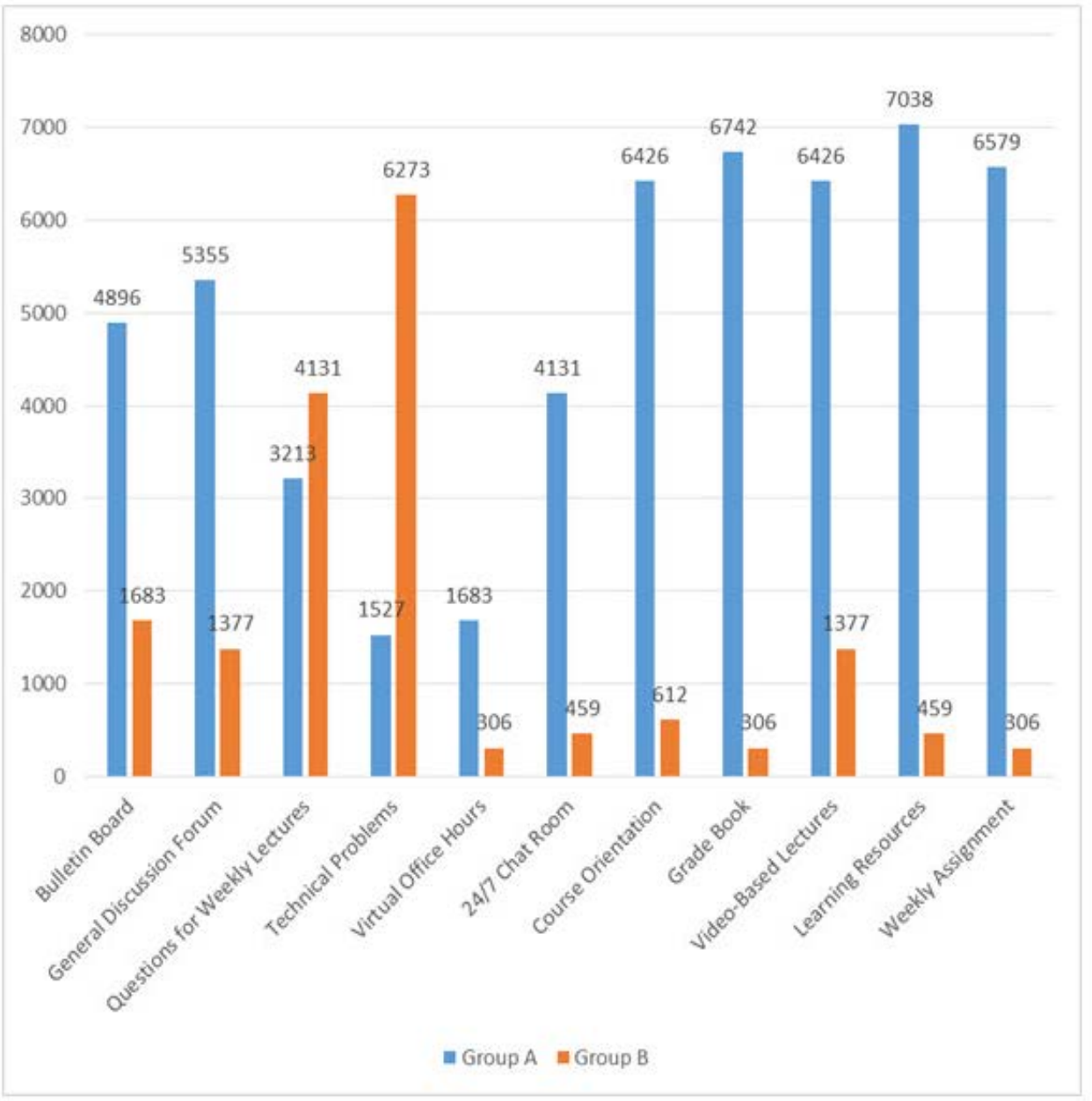

Figure 5. Learning activities viewed by learners in Group A and Group B.

\section{Discussion and Implication}

The combined findings in the online survey and learners' login analysis presented an overview of what factors lead to successful completion in an online professional development course. First of all, successful online learners in an online professional development course are in the age range of 25-34. They need to have "Self-discipline". This factor was actually in line with what previous researchers (Boyd, 2004; Beaudoin, Kutz, \& Eden, 2009) found in their studies. Second, they understand that they need to complete the course because it is their school administrators' expectation. It is interesting that this factor was not found in any previous studies about the influence of school administrators' expectation on in-service teachers' performances in online professional development. Cavanagh (2013) reported that more and more principals participate in online tools for professional growth. This, in turn, might bring about positive effects on teachers' professional development. They also need to be able to learn with limited support. This probably explained why the only two learning activities 
learners in Group A less frequently viewed in the online course were "Technical Problems" and "Virtual Office Hours" as shown in the learners' login data analysis. They could manage to find the answer or solution to their problem by themselves through participating more often in forums or viewing the lectures. "Course login frequency" is another factor leading to success. This finding in the online survey was confirmed by the data shown in the learners' login log indicating that learners in Group A logged into the online course three times more than their peers in Group B. Literally, learners in Group A logged into their course almost every day and viewed every learning activity quite equally, except "Technical Problems". There is no finding in the literature to confirm this result, but a quite similar finding in a study by Rienties, Brouwer, and Lygo-Baker (2013) validated this phenomenon. In their study, they found that successful participants in an OPD module on average spent 4 hours and 59 minutes attending and/or watching the web-videoconferencing sessions while unsuccessful counterparts only spent 2 hours and 18 minutes. Another factor that online learners need to have to be successful in OPD is "Familiarity with technology". This factor is clearly illustrated in the learners' login data. While learners in Group A viewed the "Technical Problem" forum less often, learners in Group B viewed "Technical Problems" much more frequently.

\section{Significance of the Study}

The study triangulated the perceptions of participants and their actual activities in an OPD course. Therefore, the profile of successful OPD learners is not simply imagined and created by learners. In addition, the study validates previous findings regarding characteristics of online learners and contributes to the scarcity of scholarship on the topic. The findings of this study have several implications for school administrators, OPD organizers and trainers, and in-service teachers in OPD. First of all, the "school administrator's expectation" factor provides an implication for school districts to consider communicating a clear message to in-service teachers about their expectations when teachers pursue OPD. For instance, participants in OPD should submit a report or statement and/ or certificate of OPD completion to their school administrators after the training. Second, not everyone can successfully take online learning in general and OPD for in-service teachers in particular. Before offering an OPD for in-service teachers, OPD organizers and trainers need to be aware that OPD participants need to have certain personal characteristics and skills such as "Self-discipline" and "Familiarity with technology". In other words, before conducting online professional development training, OPD organizers or trainers may create a checklist for in-service teachers to identify if they are suitable for OPD.

\section{Limitations of the Study}

The study focused on selected factors of successful online learners as reported in previous research. It is not possible to include all factors that might affect learners' success in the OPD setting. In addition, as answers to the factor survey were anonymous, the researchers did not take cultural perspectives into consideration. It is 
not known if school administrators' expectation affects participants' performance across countries or just in particular cultures. As reported in Beaudoin, Kutz, and Eden (2009), participants from Mexico had different opinions regarding school administrators' expectation from respondents from the other countries.

\section{Recommendation for Further Research}

Taking the limitations of the study into consideration, future research can validate other factors, including the newly found factor in this study, school administrators' expectations. Furthermore, it is a good idea to examine the factor across cultures. 


\section{References}

Beaudoin, M. F., Kutz, G., \&Eden, S. (2009). Experiences and opinions of e-learners: What works, what are the challenges, and what competencies ensure successful online learning. Interdisciplinary J ournal of E-Learning and Learning Objects, 5, 275-289.

Boyd, D. (2004). The characteristics of successful online learners. New Horizons in Adult Education and Human Resource Development, 18(2), 31-39.

Cavanagh, S. (2013). Rapid rise seen in use of digital tools for PD. Education Week, 6(3), 10.

Cho, M-H., \&J onassen, D. (2009). Development of the human interaction dimension of the Self-Regulated Learning Questionnaire in asynchronous online learning environments. Educational Psychology, 29(1), 117- 138.

Cho, M-H., Shen, D., \& Laffey, J . (2010). The role of metacognitive self-regulation (MSR) on social presence and sense of community in online learning environments. J ournal of Interactive Learning Research, 21(3), 297-316.

Coates, H. (2006). Student engagement in campus-based and online education. London: Routledge.

Colbert, J ., Brown, R., Choi, S., \& Thomas, S. (2008). An investigation of the impacts of teacher-driven professional development on pedagogy and student learning. Teacher Education Quarterly, 35(2), 135-154.

D'Andrade, R. (1995). The development of cognitive anthropology. Cambridge: Cambridge University Press.

Day, C. (1999). Developing teachers: The challenge of lifelong learning. London: Falmer

Dede, C. (Ed.). (2006). Online professional development for teachers: Emerging models and methods. Cambridge, MA: Harvard Education Press.

Dede,C., Ketelhut, D. J ., Whitehouse, P., Breit, L., \& McCloskey, E. (2009). A research agenda for online teacher professional development. J ournal of Teacher Education, 60(1), 8-19.

George, D., \& Mallery, P. (2009). SPSS for Windows step by step: A simple guide and reference, 17.0 update (10th ed.). Boston, MA: Allyn and Bacon.

Guichon, N. (2009). Training future language teachers to develop online tutors' competence through reflective analysis. ReCALL, 21(2), 166- 185. 
Hawley, W., \&Valli, L. (1999). The essentials for effective professional development: A new consensus. In L. Darling-Hammond \& G. Sykes (Eds.), Teaching as the learning profession: Handbook of policy and practice (pp. 127-150). San Francisco, CA: J ossey Bass.

Heiervang, E., \& Goodman, R. (2011). Advantages and limitations of web-based surveys: Evidence from a child mental health survey. Social Psychiatry and Psychiatric Epidemiology, 46(1), 69- 76.

Hodges, C. B. (2008). Self-efficacy in the context of online learning environments: A review of the literature and directions for research. Performance Improvement Quarterly, 20(3-4), 7- 25.

Hurd, S. (2006). Towards a better understanding of the dynamic role of the distance language learner: Learner perceptions of personality, motivation, roles, and approaches. Distance Education, 27(3), 303- 329.

Kelleher, J . (2003). A model for assessment-driven professional development. Phi Delta Kappan, 84(10), 751-756.

Lim, C. K. (2001). Computer self-efficacy, academic self-concept, and other predictors of satisfaction and future participation of adult distance learners. The American J ournal of Distance Education, 15(2), 41- 50.

Maxwell, J . A. (2005). Qualitative research design: An interactive approach (2nd ed.). Thousand Oaks, CA: Sage.

McGhee, R. M. H. (2010). Asynchronous interaction, online technologies self-efficacy and self-regulated learning as predictors of academic achievement in an online class (Doctoral dissertation). Baton Rouge, LA: Southern University and Agricultural and Mechanical College.

Murphy-Latta, T. (2008). A comparative study of professional development utilizing the Missouri commissioner's award of excellence and indicators of student achievement. ProQuest. ISBN 9780549489900. Retrieved 2013-08-12.

O’Dwyer, L. M., Masters, J., Dash, S., De Kramer, R. M., Humez, A., \& Russell, M. (2010). E-learning for educators: Effects of online professional development on teachers and their students. Retrieved from http:// www.bc.edu/ research/intasc/PDF/ EFE_Findings2010_Report.pdf

Palloff, R., \& Pratt, K. (2001). Lessons from the cyberspace classroom. San Francisco, CA: J osseyBass.

Rienties, B., Brouwer, N., \&Lygo-Baker, S. (2013). The effects of online professional development on higher education teachers' beliefs and intentions towards 
learning facilitation and technology. Teaching and Teacher Education, 29, 122131.

Russell, M., Carey, R., Kleiman, G., \&Venable, J . D. (2009). Face-to-face and online professional development for mathematics teachers: A comparative study. J ournal of Asynchronous Learning Networks, 13(2), 71- 87.

Shultz, S., Hoffman, C., \& Reiter-Palmon, R. (2005). Using archival data for I-O research: Advantages, pitfalls, sources, and examples. Psychology Faculty Publications, 5. Retrieved from http:// digitalcommons.unomaha.edu/psychfacpub/ 5

Stanford-Bowers, D. E. (2008). Persistence in online classes: A study of perceptions among community college stakeholders. J ournal of Online Learning and Teaching, 4(1), 37- 50.

Stes, A., De Maeyer, S., Gijbels, D., \& Van Petegem, P. (2012). Instructional development for teacher in higher education: Effects on students' learning outcomes. Teaching in Higher Education, 17(3), 295-308.

Stes, A., Min-Leliveld, M., Gijbels, D., \&Van Petegem, P. (2010). The impact of instructional development in higher education: the state-of-the-art of the research. Educational Research Review, 5(1), 25-49.

Sun, S. Y. H. (2014). Learner perspectives on fully online language learning. Distance Education, 35(1), 18-42.

Treacy, B., Kleiman, G., \&Peterson, K. (2002). Successful online professional development. Leading \& Learning with Technology, 30(1), 42- 47.

Wang, M. J . (2010). Online collaboration and offline interaction between students using asynchronous tolls in blended learning. Australasian J ournal of Educational Technology, 26, 830-846.

Womble, J . (2008). E-learning: The relationship among learner satisfaction, selfefficacy, and usefulness. The Business Review, 10(1), 182- 188.

Yang, S. C., \& Liu, S. F. (2004). Case study of online workshop for the professional development of teachers. Computers in Human Behavior, 20, 733- 761.

\section{Athabasca University $\mathbf{a}$}

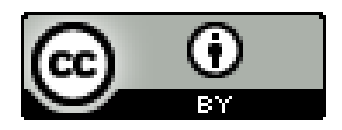

